\title{
Albert Hirschman and his controversial research report
}

\author{
ANA MARia Bianchi
}

Working PAPER SERIES № 2011-03 


\title{
DEPARTMENT OF ECONOMICS, FEA-USP \\ WORKING PAPER № 2011-03
}

\section{Albert Hirschman and his controversial research report}

\author{
Ana Maria Bianchi (amafbian@usp.br)
}

\begin{abstract}
:
During the early nineteen sixties, Albert Hirschman negotiated with the International Bank of Reconstruction and Development, part of the World Bank group, the financial support that he needed for an extended visit to several WB development projects scattered throughout the poor areas of the world. The document where he reports his visit was the matter of much controversy between the IBRD staff and Hirschman. One of the major points of disagreement was the latter's refusal to employ the technique of cost-benefit analysis, then very popular at the $\mathrm{WB}$, as a measure of the success of a project. Hirschman claimed that a one-dimensional scale was unable to grasp the various indirect effects of a project, which, he argued, were so varied as to escape detection by one or even several criteria uniformly applied to all projects.

The paper claims that the strong negative reaction that Hirschman found among the WB economists was a crucial factor in his decision to leave the strict realm of economics and to embrace the broader social sciences themes of his subsequent writings.
\end{abstract}

Keywords: Hirschman, World Bank, economic development, development economics

JEL Codes: B20, B31, 01 


\title{
Albert Hirschman and his controversial research report ${ }^{1}$
}

\author{
Ana Maria Bianchi \\ Full Professor \\ University of São Paulo
}

In 1967, the Brookings Institution published a book by Albert O. Hirschman, entitled Development Projects Observed. The book derived from a research report that the author had written for the International Bank for Reconstruction and Development (IBRD, hereafter refered to as International Bank), one of the component institutions of the World Bank. It contains the observations from an extended visit by Hirschman during the 1960s to eight regional development projects scattered throughout the world, in Latin America, Asia, Africa and Europe itself.

The purpose of this article is to reconstruct the path followed by Hirschman from the original project assembled to raise funds for his program of visits until the publication of the book in which he recounted the results of these. The background to this project is provided by the missions of foreign specialists sent to countries of the so-called "Third World" during the period extending from the end of the $19^{\text {th }}$ century to the 1960s. These missions prepared the ground for the conception and implementation of regional development projects, on the lines of those designed by the World Bank. In his capacity as a "money doctor", Albert Hirschman took part in some of these missions. As a researcher and academic, he was active in consolidating the new field of development economics.

The objective of reconstructing the background to the drafting of Hirschman's report is also present in Alacevich (2008) and somewhat in Mason \& Asher (1973), who highlight Hirschman's pioneering role in the creation of a system for evaluating projects within institutions such as the World Bank. Unlike these two, however, my study falls within the field of the history of economic thought. I claim here that the negative repercussions of Hirschman's report among the technicians of the International Bank were due to the fact that the author decided to follow his own path, dictated by his convictions regarding the mechanics of development and by his critical stance with regard to the methods for evaluating projects which were then routine.

${ }^{1}$ I would like to thank the CNPq for its support for the realization of this study. Previous versions were presented at the weekly seminar of the EAESP-FGV, at the VI Meeting of the Iberian Association for the History of Economic Thought and at the History of Economics Society Annual Conference. I received useful comments from Teresa Rangil. 
The article starts from a brief reconstitution of important biographical data to locate the context in which Hirschmann's visit to the World Bank projects took place. The following sections adopt a chronological order. In the first one, I describe the negotiations undertaken by Hirschman with the technicians and directors of the International Bank, which began in Spring 1963 and continued in 1964, when the author made his first field visit. I then focus on the rather turbulent intermediate stage of the process, during which Hirschman edited the first version of his visit report. There were many caustic criticisms, to the point of considering the possibility of prohibiting the book's publication. The outcome of this dispute represented a turning point in Hirschman's career. This is the focus of the fifth part of the article, which deals with the intellectual trajectory of the author, who at this point was completing his trilogy in the field of development

economics. $^{2}$ My working hypothesis is that the tensions experienced by Hirschman were the last straw in his decision to abandon economics and to move to the nearby field of social sciences. A concluding section closes the paper.

\section{$\underline{\text { Some biographical details }}$}

A few biographical details help to place Albert Hirschman's role in context as a foreign economic adviser, whose trips to Third World countries in the 1950s and 1960s were sponsored by the International Bank. As I described in a previous article (Bianchi 2007), Hirschman disembarked in the United States in January 1941 from the ship Excalibur, arriving from Lisbon. ${ }^{3}$ He was a refugee from Nazism, and found shelter after a tumultuous escape via the Iberian Peninsula. Thanks to a grant from the Rockefeller Foundation, which he used during an initial two-year period, he was able to dedicate himself to the detailed study of international trade statistics as a research assistant at the University of California. In June 1941, he married Sarah Chapiro, who at the time was a student at the University.

After serving in the US army, to which he was recruited on account of his fluency in French, German and Italian, Hirschman began working for the advisory department of the Federal Reserve System. His duties consisted of monitoring the execution of the Marshall Plan, which, as is known, had the objective of solving the problems of the economic recovery of a Europe devastated by war.

${ }^{2}$ The first two books of the trilogy, The Strategy of Economic Development and Journeys Toward Progress, were published in 1958 and 1963 respectively. As the author states in the preface to

Development Projects, the three books were conceived as a coordinated sequence to celebrate "the epic of development”. (Hirschman 1967, p. viii).

${ }^{3}$ RF Recorder Cards, Series Humanitas, Rockefeller Archive Center. 
Hirschman's career as a money doctor began in 1952, when he was sent to Colombia at the indication of the International Bank, to serve as an adviser to the government. He spent more than four years in Colombia, working for the government and also as a consultant for private business groups. In 1957 he returned to the United States, becoming a member of the teaching staff of prestigious universities and devoting himself to his two first books on economic development, The Strategy of Economic Development, and Journeys toward Progress. ${ }^{4}$

Unlike other foreign specialists and even the economists with whom he associated at the International Bank, such as Lauchlin Currie and Paul Rosenstein-Rodan, Hirschman showed a constant skepticism regarding the effectiveness of large-scale integrated development plans. In his capacity as adviser to the Bank he favored smaller scale projects, capable of generating linkage effects on the local economy, one of the favorite theses of his development economics. Periodic field trips, such as the one that he proposed to the directors of the institution, would be essential to ensure the success of these localized projects.

Hirschman's approach was theoretical and practical at the same time. In his view, not only was a new theoretical approach necessary to strengthen the recently founded field of development economics, it was also essential for its concepts and hypotheses to be supported by meticulous case studies. ${ }^{5}$ It was this double concern that guided the elaboration of a project to obtain support for a visit to development projects spread throughout the world.

\section{The negotiation of the proposal}

${ }^{4}$ In Adelman (2008), there is an interesting report on Hirschman’s professional experience during his stay in Colombia and during the years immediately following it.

${ }^{5}$ On this point, it is curious, to say the least, that Paul Krugman (1994) placed Hirschman in the group of economists who developed what he called the "high theory" of development. Krugman alleges that the progressive failure of this type of approach during the 1950s was due to the loss of confidence on allinclusive development models, and also to the difficulty that these economists experienced in adapting themselves to the increasingly mathematical rhetoric of economic theory. A brief comment is appropriate, here. While it is true that Hirschman did not exhibit a level of mathematical sophistication comparable to that of more recent economic literature, the fact remains that his writings have a more microeconomic approach which, according to Krugman, characterized the emerging research. As Alacevich (2008) states, Hirschman is a representative of the period in which 'high theory' had ceded its place to more 'micro' approaches. 
Hirschman began to plan his visit to the International Bank's projects in 1963, when he was a professor of International Economic Relations at the University of Columbia in New York. In the original proposal, the extensive planned visit would coincide with a year's sabbatical from this university.

The visit ultimately extended from July 1964 to August 1965. Hirschman’s wife, Sarah Hirschman, accompanied him as research assistant. The couple left their New York apartment at 350 Central Park West to carry out a detailed investigation of 11 projects on different continents: in Europe (Italy), Latin America (El Salvador, Ecuador, Peru and Uruguay), Asia (Bangladesh, Thailand and India) and Africa (Uganda, Ethiopia and Nigeria).

The selection of projects to be visited was drafted jointly with the International Bank's technicians in 19645. Initially, the list was drawn up at the headquarters of the Bank in Washington, D.C. and subsequently on the basis of preliminary field visits. Two criteria were considered: firstly, the project had to cover a variety of sectors of activity and geographical areas: "the sample should include projects in as many fields as possible". ${ }^{6}$ According to the proposal, the diversity of experiences extracted from the projects should be attributed to their structural characteristics. Such characteristics not only involved economic and technological attributes, but also organizational and administrative properties.

As a second prerequisite for the selection of projects, these would have to have a relatively long history, corresponding to a minimum period of five years of operation: “...this study will concentrate on a limited number of Bank-assisted projects whose effects on development can begin to be evaluated because sufficient time has elapsed since these projects have been in operation". 7

In practice, this second criterion entailed that research would be concentrated on the older projects, which the Bank had already supported in their initial years of operation. As shall be seen, this was the focus of criticism against both the original proposal and the report drawn up after the fieldwork. According to the critics, the oldest projects were not the best projects in operation, since they presented defects that had being perceived and remedied over time.

Hirschman's proposal merited criticism from Burke Knapp, the then deputy chairman of the institution, and from his staff. ${ }^{8}$ The accusation was that it was excessively directed towards the consideration of 'side-

6 "A study of completed investment projects which have received financial support from the World Bank". WB Archives, June 1963, ISN\#61705 ACC \# 194-02, Box 41.

7 "A study of completed investment projects which have received financial support from the World Bank". WB Archives, ISN\#61705 ACC \# 194-02, Box 41.

${ }^{8}$ WB Archives, ISN\#61705 ACC \# 194-02, Box 41. 
effects', to the detriment of the actual economic results obtained by the projects. This criticism was not isolated and continued to be made after the report had been concluded.

In reply to the criticisms, Hirschman drew up a second version of the proposal, in which he identified foci for analyzing the effectiveness of the projects to be visited. He offered to research the process of political decision-making under two distinct conditions, namely, in the country where the project was located (specific groups and interests involved) and within the International Bank itself, before and after the implementation of the project. In this second aspect, he dealt with the question of cost-benefit analysis, a technique widely used at the time by technicians of the institution. Hirschman made his opinion on this procedure clearly known: according to him, analyses of this type could lead to underestimation of costs ("as is frequently the case”) and of benefits (“also frequent”) by in-house analysts. ${ }^{9}$

Another focus of analysis defined in the second version of Hirschman's proposal was a retrospective evaluation of the project, more specifically of the results obtained during the implementation period and afterwards. It would evaluate its linkage effects on economic activity in the region, but beyond these, its longer term consequences, as was the case for its impacts on income distribution, wealth and power. ${ }^{10}$

This was another point to which the consultants of the International Bank reacted negatively. For the technicians, the evaluation should give priority to the economic aspects of the projects, since, according to them, the typically social aspects would be secondary from the perspective of an appropriate evaluation of their progress. $^{11}$

As shall be discussed below, this attention by Hirschman to the so-called side-effects was no accident, nor was it an occasional aspect of his stance as a researcher. It derived, on the one hand, from his tendency to despise disciplinary barriers and investigate the multiple dimensions of each social phenomenon. On the other hand, it translated a deeply held conviction, which had already emerged in his previous writings, that

${ }^{9}$ The criticism was not new, nor had a long interval passed since it had been made. As Lepenies (2009) argues, analyses based on the estimation of costs and benefits err in presupposing that the future is predictable and hence, that it is possible to anticipate the failures and successes of a given policy.

${ }^{10}$ WB Archives, Albert O. Hirschman, "A study of completed investment projects which have received financial support from the World Bank”, June 1963.

${ }^{11}$ Curiously, the same type of criticism had been made years before on the report by Lauchlin Currie, a Canadian economist who was appointed to head a mission of specialists sent to Colombia before Hirschman had moved there. As I recounted in a previous article (Bianchi 2010), relations between Hirschman and Currie were strained, despite the social concern that both revealed in their consulting activities. 
unexpected effects, not captured in the economic calculation of benefits, could represent the greatest capital of a project.

In the second version of his proposal, Hirschman made some concessions to his critics. He still insisted on the need for a "qualitative" evaluation of projects. However, without renouncing his original goal of concentrating on the investigation of linkage effects, he introduced the notion of costs and benefits. In this way, he added to his listing of questions to be evaluated: "b) were there any unexpected indirect benefits and linkage effects? c) did the project give rise to unforeseen direct or indirect social or economic costs?”

Foreseeing future difficulties of understanding while still in the negotiation phase, Hirschman proposed that the International Bank could not veto paragraphs, chapters, sections or sentences of the book which would be published on the basis of the report. ${ }^{12}$ Through its Deputy Chairman, the Bank retorted that it could not give a categoric guarantee here. Notwithstanding this, it replied in a conciliatory tone that it was very unlikely that glaring differences of opinion would be found between Hirschman and the Bank's staff. ${ }^{13}$

In order to achieve closure on this pending item and with the aim of accommodating the divergences and minimizing the scope for conflict, the International Bank suggested that the final sentences of Hirschman's proposal be changed. Firstly, he would undertake to show the final manuscript to the staff before submitting it for publication. If there was no veto, it would be published. If there were, a second clause stipulated that the International Bank could determine that the manuscript would not appear as an official publication of the institution. This alternative was ultimately the one that prevailed.

On March 26, 1964, Hirschman finally reached an agreement with the Bank, according to which the latter would not insist on its power of veto over the publication of any manuscript that he might write. ${ }^{14}$ This was confirmed in the preface that Kermit Gordon, the then Chairman of the World Bank, wrote for the book Development Projects, in which he highlighted: ...”The bank bears no responsibility for the views expressed and the conclusions reached."

${ }^{12}$ It is important to highlight that the collaboration of the Brookings Institution, which would be responsible for the publication of the book resulting from the study, was already stipulated in Hirschman's initial proposal to the International Bank.

${ }^{13} \mathrm{~B}-\mathrm{K}$ to AOH: "I should be surprised if there turned out to be any strong difference of opinion between you and us.” ISN\#61705 ACC \# 194-02 Box 41.

${ }^{14}$ GDW to ERB, both Chairmen of the World Bank during the periods 1963-68 and 1949-62, respectively. 
Criticisms remained on the representativeness of the sample to be visited. ${ }^{15}$ Despite these, Hirschman received the official support of the International Bank, including funding for hiring a research assistant.

\section{The visit report and its troubled course}

In August 1965, after completing his prolonged schedule of visits to projects located on three continents, Hirschman submitted a preliminary report to the Bank, entitled “A study of selected WB projects - Some interim observations" (hereafter referred to as SSWBP). ${ }^{16}$

Hirschman's report constituted a "dummy version” of the book that he would publish. He combined a brief description of the visits made to the various projects with observations of a more general character on supporting activities for development. Indeed, the script expressed this effort to extract broader conclusions on the basis of characteristics common to the projects examined in detail. In accordance with his convictions regarding the best evaluation strategy, Hirschman highlighted in the report that case studies are an essential tool for the detection of universal patterns, if, when and to the extent that these patterns exist.

Invited to express an opinion on Hirschman's project, a specialist linked to the International Bank praised it, arguing that it probably represented the first attempt to create a standardized mechanism for the $a$ posteriori evaluation of the success of an infrastructure project. ${ }^{17}$ This opinion was shared by other specialists who were consulted. As claimed by Alacevich (2008), the post mortem evaluation of development projects is a fundamental activity for an institution which central activity is that of granting loans. This activity only became operational within the International Bank at the start of the 1970s, partially by virtue of the discussion raised by the publication of Hirschman's report.

From the perspective of assembling an evaluation system, Hirschman's contribution was of strategic importance. Notwithstanding the criticisms aimed at his report, he provided the World Bank with a concrete opportunity for reflection on methods for evaluating the repercussion of its policies in less developed countries. Mason and Asher (1973, p. 251) explicitly acknowledged this merit, recalling that until that time the functions of evaluating projects were in the hands of engineers and financial analysts. The former concerned themselves with determining the quantities of materials necessary for the implementation of the project; the latter calculated rates of return and were concerned with sources of funding and monetary flows. There was nevertheless a lack of a more global evaluation of the performance

\footnotetext{
15 24/2/1964, memo, PMM to WD.

${ }^{16}$ WB Archives, Box 1070156.

17 18/2/1964, DA to Department Heads, International Bank and IFC, WB Hirschman Folders, vol. I.
} 
of projects that were already fully operational in all of their dimensions and this was precisely the motivation of Hirschman's mission.

It should be pointed out that not all of these specialists invited by the International Bank to read Hirschman's report evaluated it negatively. Rowing against the current, one of them praised Hirschman's tenacity in defending the need to go beyond the examination of the purely economic aspects of the projects. In a letter to Hirschman, he states that, with some elaboration, his report might avoid the "future inhibitory role of economists”. In his precise words:

“I read your chapter I... and enjoyed it. You've helped in part to remove the unease that I have had in reflecting on the fact that if our modern project techniques had been used, much of the existing development in the world would not have been undertaken. It may be that with a further working out of the idea that you explore in this chapter, we can avoid this future inhibitory role of economists." 18

As a concrete consequence of this pioneering effort, the organizational structure of the International Bank was reformulated to accommodate a specific department responsible for evaluation tasks. As a first stage, this took the form of a Programming and Budget Department, and as a second, the form of an Operations Evaluation Department (Alacevich 2008, p. 9).

The report with Hirschman's provisional observations circulated widely among the technicians of the International Bank. It received criticisms, some extremely severe, which leave no doubts as to the differences in viewpoints. In some of them there is the reiteration of the criticisms of the original proposal, demonstrating that the objections to Hirschman's approach were not duly overcome during the negotiation phase of the project. In other words, neither did Hirschman completely renounce his original proposals nor did the International Bank’s staff dilute their criticisms.

The criticisms were principally directed towards the following aspects of the report: 1) sampling criteria for the projects; 2) attention considered to be excessive to "collateral" aspects and, by association, to the hypothesis of unexpected effects; 3) a supposed identification of the author with the interests of the beneficiaries, to the detriment of the interests of the International Bank; 4) Hirschman's explicit objections to the calculation of rates of return, which would have entailed the lack of operational utility of the report; 5) lastly, the style of the report, which was considered to be academic.

An account of the criticisms shall be made in accordance with this classification.

\section{Sampling criteria}

${ }^{18}$ 28/10/1966, AWK to AH, ISN\#61705 ACC \# 194-02 Box 41. 
The criticisms of this type focused on the lack of representativeness that the projects selected for the visit would have in terms of the most recent practices of the International Bank.

One of the technicians who was called to pronounce on the report had two points in common with Hirschman: he was a refugee from the Nazis and had had a previous professional commitment at the Federal Reserve. His specialization was the area of transport and this was the target of his criticisms. In his first comments, the specialist highlighted Hirschman's ignorance of the evaluation practices adopted by the International Bank during the most recent period, as well as of the actual progress of new projects in operation. In this way, he argued that "at least with regard to transport", the economic evaluation practices of the projects had been substantially improved in recent years. In view of this, some of the recommendations that Hirschman presented as being a major innovation were actually fully incorporated into the current evaluation system. Ultimately, this technician suggested that Hirschman was not only frivolous in his comments but had been negligent, since he had not read the most recent reports issued by the institution, based on its most recent experience. This point would reappear in other criticisms.

\section{Collateral aspects and unexpected effects}

The emphasis that Hirschman gave to the "collateral" aspects of projects formed the object of various questionings. It is directly linked to the social dimensions of the projects, which carried considerable weight in his considerations.

In this way, in an internal memorandum, one of the readers of the report complained that Hirschman placed excessive emphasis on the social aspects, to the detriment of the economic ones (16/11/65, PAR to LJCE). The same technician attributed this emphasis on social aspects to the visit that Hirschman had made to the FAO (Food and Agriculture Organization), an institution of the United Nations, during his research in the field. The time dedicated to these visits was alleged to be excessive and to have diverted attention from the economic and technological aspects of the projects.

The attention that Hirschman gave to the social aspects of each project cannot be dissociated from his hypothesis regarding the occurrence of unexpected effects. According to him, having concluded the implementation phase of a given project, the emergence of surprising patterns was common, with these deriving from what he termed "hidden rationalities" that had a positive impact on the performance of the project.

Right at the start of his report, Hirschman (SSWBP, p. 2) noted the distance separating the effective progress of the projects from their original proposal. The author points to unforeseen results that assailed a number of projects that he visited. Divergences with regard to the original objectives had the effect of generating unknown, uncertain and unexpected elements of such projects: "The element of the unknown, the uncertain and the unexpected which deflects projects from the originally chartered course is considerable in all projects.” Far from lamenting this change in course, however, the author commented on the positive consequences that it triggers. 
The best illustration of this confidence in unexpected effects is given by the pulp and paper project in Pakistan. Symptomatically, Hirschman chose this case to head his entire report. The description of the experience is given in a poetic tone. He commented on the good fortune surrounding the project, despite a major underestimate of the supply of raw material, in this case, bamboo, for the manufacture of paper:

"Looking backward, it may be said that the Karnaphuli mill was 'lucky': its planners had badly overestimated the permanent availability of bamboo but the mill escaped the possibly disastrous consequences of this error by an offsetting underestimate or, more correctly, by the unsuspected availability of alternative raw materials.” (SSWBP)

The unavailability of bamboo was not detrimental, since it generated backward linkage effects, which stimulated the supply of substitute imports, and even more importantly, active work on the revitalization of forests. But was this happy consequence a mere product of chance? Hirschman suspected that it was not and referred to equally positive occurrences in other Bank projects. The irrigation project in Peru suffered substantial delays due to changes in political power and indecision in the measures necessary to make it possible. Nevertheless, this delay ultimately favored a successful land reform, by subdividing land into viable family properties with a compatible credit system. Likewise, delays in political and administrative decisions in Uruguay permitted the development of experimental and applied research, which made possible the servicing of a significantly larger area of pasture than was initially foreseen.

In other words, Hirschman praised the difficulties encountered by such projects and, at first sight paradoxically, located the secret of their success in them. He introduced the topic of hidden rationalities, to which he would again draw attention in the body of the report and which would become a favorite theme of his subsequent works. Hidden rationalities are occasionally triggered by regular patterns that are found in real trajectories, the path of which initially appears to be disorganized. ${ }^{19}$

Hirschman dedicated one of his sections to the theme of side effects, which permeate practically the entire report. Starting from its title: "Project appraisal: the centrality of side-effects", the entire text is provocative. In suggesting the centrality of effects that are improperly labeled "side-effects", Hirschman established a trademark of his style, which is fed by paradoxes. He classified the expected effects of a given project into two categories: unsuspected threats, on the one hand; and equally unsuspected remedies for these threats. This second group included creative solutions which, far from entailing the failure of the

${ }^{19}$ As the author observed in his notes on his visit to an irrigation project in Thailand: "In irrigation projects there always seems to be a shortfall of water availabilities with respect to expectations... Is this a general phenomenon? Isn't it the same phenomenon that I just noticed in KPM - overestimate of adaptability of technology and underestimate of resourcefulness in achieving required adaptation?” (AOH Papers, G.S. Mudd Library, box 13). 
project, revealed themselves as a high point of its implementation. In this way, when a project was implemented, a learning process was triggered which, if exploited to good effect, might lead to the discovery of hidden rationalities. ${ }^{20}$

Frobert and Ferraton (2003, p. 128) correctly point out that Hirschman did not see the hiding hand principle as a panacea. There was no guarantee of a happy ending in all cases, and Hirschman conceded that the overcoming of difficulties was not a necessary result. By comparing the railway project in Nigeria with an alternative of transport by truck, the author warned that the existence of problems did not constitute in itself a sufficient condition for a creative response. The inter-ethnic conflicts observed in the African country and a high level of corruption prevented the creation of a climate of harmony and co-operation necessary for the success of the railroad project. Hirschman even created a new noun, "Nigerianization", with which he designated the replacement of expatriates by local staff without the same technical qualifications.

\section{Identification with the interests of beneficiaries}

Hirschman's report received a further criticism with particularly severe implications. Some of the specialists highlighted the identification of the author with the interests of the beneficiaries of the projects. As a result of this, he had failed to take into consideration the interests of the International Bank itself, with the sponsorship of which he carried out his visits.

In this way, a technician pointed out that the report had interesting insights "but many debatable points". 21 He complained of the partiality of the judgment, which ultimately he denoted as a "lack of solidarity" with the viewpoint of the technicians of the institution that had supported his research. Hirschman, the technician stated, did not appear to have examined every side of the questions which he highlighted, particularly the viewpoint of the Bank's technicians, who were more familiar with the projects. His critique of the autonomous agencies illustrated this inadequacy.

This point deserves more clarification. In a certain section of his report, Hirschman complained of the rule established by the International Bank, according to which, external loans should be channeled via autonomous agencies. The justification for this rule was to permit insulation from political injunctions. By operating through autonomous agencies, the International Bank would have access to a contact that was less susceptible to the particular interests of whichever group was in power at the time.

What did Hirschman have against this mechanism? His argument was that with the establishment of an autonomous agency, direct access would be lost to the central political power of the country in which the

\footnotetext{
${ }^{20}$ We find here a clear germ of the concept of cognitive dissonance, which would take on a central role in certain currents of economics, and which had an important precursor in Hirschman.
}

${ }^{21} 17 / 9 / 65$, memo, WCB to BC. 
project was established. Creating an autonomous agency was already a difficult task, but guaranteeing the success of its operation as a mediator would be even more problematic. The price to be paid to guarantee immunity with regard to political pressures would be very high, since the project would lose its legitimacy with the authorities of the country that benefited from the loan.

Reflecting the complaints of local government, Hirschman also referred to the possibility of domestic borrowers being overlooked in favor of international autonomous agencies: “...complaints were heard in some countries about the de facto discrimination against domestic contractors and in favor of large international firms." ((SSWBP, p.10) Some autonomous agencies, designed to imbue the old order with the new spirit on the contrary allowed themselves to be infiltrated by this old order. This allegedly occurred in the case of the railroads in Nigeria and in the Vale do São Francisco, in Brazil.

The reply of the International Bank consultant comes across in his comments on the report, with him basically alleging that while the International Bank did recommend autonomous agencies, it did not have a set position on the need for them. ${ }^{22}$ On the contrary, despite the highly reasonable foundations on which this rule is based, it could always be bypassed whenever it proved inappropriate to the concrete situations. The International Bank did not have a doctrinaire view on the point and did not consider it essential to assign the operation of railroads and ports to the same parties.

Once again, this negative comment attributes to Hirschman a lack of knowledge of the de facto policies followed in the International Bank project. For the consulted analyst, the report raised doubts as to whether Hirschman had examined every angle of the questions considered, particularly from the perspective of the bodies responsible for the conduct of the projects: "At this point I question whether he has examined all sides of the questions, more particularly the point of view of those in the Bank most familiar with the projects.",23

The above observations show that the technicians questioned the impartiality of Hirschman's opinions and his own perception of the facts that he compiled during his field visits. There was nevertheless an expectation that this impartiality would not be transferred to the book. As the technician states "But we should be sure that Mr. Hirschman has access to all the facts, and all the points of view, before he completes his book." ${ }^{24}$ The technician in turn lamented with a certain irony the negative tone of Hirschman's report, which, he believed, should be attributed to his academic or perhaps even literary bias:

\footnotetext{
22 17/9/65, memo, WCB to BC.

${ }^{23}$ 17/9/65, memo, WCB to BC - emphasis.

${ }^{24} 17 / 9 / 65$, memo, WCB to BC.
} 
"In the academic and literary professions, criticism seems to draw higher marks than does praise, and while Mr. Hirschman is very knowledgeable and capable, he may not be above succumbing to this temptation.” A similar bias is highlighted by another International Bank technician, who submitted his comments directly to Hirschman. He argued that many of the author's observations "are not unreasonable, but tend to be unilateral” (22/9/65, memo, BR to CPM). He suggested that all of Hirschman's sympathy was directed towards the beneficiaries of the loans. On account of this, Hirschman committed the sin of a certain lack of balance: "A more balanced vision could have emerged if the author had paid more attention to the view of the Bank's staff than he gave to the view of the borrowers." He further complained of the imprecise character of the evaluation of uncertainties to which Hirschman referred, associated with the unforeseen consequences of the implementation of the projects. He concluded that an "intuitive appreciation of uncertainties", such as that suggested by the author, was not a good means for generating reliable generalizations.

\section{Lack of operational utility}

The criticism of the lack of utility of the evaluation process suggested by Hirschman emerges from the internal correspondence between the International Bank's technicians. It unveils reluctance on the part of the author to adopt the technique for calculating rates of return. This procedure had become routine within the institution, and was considered crucial for the comparative evaluation of the merits of a project, since it was a synthetic indicator.

Before moving on to the criticisms, it is important to give a brief summary of Hirschman's opinion regarding the analytical tool based on the calculation of rates of return. Already in the first pages of his report, Hirschman clearly stated his reluctance to adopt this type of technique: "I must dispel right away any expectation that my study will yield a convenient set of statistics which will make it possible to rank the projects studied in terms of the benefits they have yielded per investment dollar.”(SSWBP, p.2) He nevertheless adopted a cautious tone in his criticism. As he stated in a footnote, his objective was to "supplement" the evaluation techniques in use within the institution, and not to replace them.

Hirschman's resistance must be attributed to the more general conception of the author of the type of analysis that should guide the evaluation of projects. In one of these sections of his final report, reproduced in the book published by Brookings, Hirschman qualified cost-benefit analysis as part of an "offensive against collateral effects", since it was based on a conception incompatible with his own, which, as seen, attributed a value to the possibility of occurrence of such effects. The calculation of benefits required by the technique was, he claimed, based on many arbitrary assumptions, resulting in a "misguided, even if heroic, attempt at quantification” (reproduced in Development Projects, p. 175).

Hirschman continued with his criticism by arguing that the transposition of this technique to "less fortunate" regions was problematic, due to the major assumptions on which it was based. Under these conditions, he said, it is impossible to assume stable growth, full employment or perfect mobility of people 
and capital. A comparison of the technique in question with the concept of forward and backward linkages, which he himself introduced in previous works, would be unfavorable to the former. In this way, while the idea of linkages would be fully enshrined in the analysis of industrialization projects and in the weighting of priorities for sectors, subsectors and projects, the same could not be said of cost-benefit analysis, which would remain the target for staunch criticism.

Why, Hirschman enquired, did economists allegedly react unfavorably to the idea of collateral effects and, instead, favor the calculation of rates of return? (The reference here is to the International Bank's economists, but Hirschman did not go so far as to state this). Certainly because they were looking for a single ordering instrument which would succeed in uniting the various economic dimensions of a project in a single indicator. Hirschman immediately qualified the search as "futile": how could it be possible to order development projects on a single scale, on the basis of a single synthetic indicator capable of aggregating all of their dimensions?

In adopting this precarious analytical mechanism for evaluating projects, he continued, foreign specialists of development agencies, appointed by lenders, would remove themselves from any responsibility for the final decision of the borrowers. If these latter parties departed from the recommendation, they were victims of the negative influence of "political factors", considered as equivalent to non-rational factors. In the author's own words:

Political is here equated with irrational, if not worse; the heavy price for the unique ranking is the fact that, with many important considerations excluded from the technician's purview, the decision maker will in the end make more rather than less use of his intuition and "seat-of-the-pants" judgment than if the technicians had set themselves the more modest goal of comparing projects according to a limited number of criteria. (SSWBP, p....)

The criticisms of the report revealed the difference in points of view. For a technician, Hirschman's recommendation, in the sense of appreciating political and social factors, was a double-edged sword. This technician argued specifically that one of the major assets of the International Bank was its deliberate policy of restricting its concerns to specifically economic criteria. This would provide immunity to the evaluator from political pressures, with the secret of successful advice lying therein. ${ }^{25}$

In this way, the reply of these specialists to Hirschman's criticisms was based on a defense of cost-benefit analysis as a useful, albeit not exclusive, instrument by which the success of projects would be judged. In practice, said one of them, it was unlikely that the decisions of the International Bank would be taken solely on the basis of the cost-benefit ratio, "even in sectors where this ratio is more useful". On the contrary, in

25 17/9/65, WCB to BC. 
their evaluation work for a given project, the technicians would ultimately make a sustained effort to visualize the uncertainties to which Hirschman referred in his hypothesis of hidden rationalities. ${ }^{26}$

The speaker continues with his defense of current practices, criticizing the previously mentioned lack of dialogue between Hirschman and the institution's technicians. According to him, the latter party would have perceived this if he had had more opportunity to discuss some of his cases with the staff of the International Bank who worked on the projects that he visited.

Another technician commented that Hirschman' manuscript did not contain any "operationally useful" analysis, either of the merits and priority of the projects visited or of the changes which could be made to improve them. The principal weakness of the report was, in his view, the undue emphasis on secondary factors and effects. For this critic, the thesis that collateral effects could paradoxically be transformed into social ones was absolutely unreasonable. ${ }^{27}$

The same critic used irony with regard to the principle of the hiding hand, which would support the idea of hidden rationalities. The technician says that if well understood, this principle would result in absurd decisions. Adopting it would lead to recommendations to development agencies that they should specifically give priority to projects with greater difficulties, since only in this way would it be possible to stimulate the ability of its administrators to overcome bottlenecks. He adds that despite the persuasive way in which it was presented, Hirschman's argument would not stand up to a lengthier analysis. Furthermore, it would never be accepted: "Fortunately, while the argumentation is cleverly presented, few readers are likely to take it seriously.,28

Another memorandum repeated this criticism that Hirschman's conclusions had limited applicability, attributing this to his lack of knowledge of the recent and considerable evolution in the practices adopted by the International Bank for the evaluation of projects. The progress in these techniques could only be perceived in the newer projects. On this point, the technician suggested Hirschman's ignorance of current International Bank practices: "It may therefore be useful for Hirschman to read some of our recent reports to determine for himself to what extent his suggestions are still relevant”. ${ }^{29}$

${ }^{26}$ On this issue, it is also interesting to read the testimony of Robert Picciotto, who contacted Hirschman in 1964, immediately before the latter's field trips. Picciotto, who would later head the World Bank's evaluation department, agreed that the task of evaluation could not be confined to the calculation of rates of return.

(Picciotto 1994)

27 13/9/65, RHD to REA, box 41, 184140B.

${ }^{28}$ 13/9/65, RHD to REA, box 41, 184140B.

${ }^{29}$ 22/9/65, HAA, memo. 
Even more favorable critics insisted on this question of operationality. One technician says that he would not criticize the contents of the report strictly speaking, but demanded new measures by Hirschman. He should prepare an "operational version" of his book, or at least add an operational chapter to it (18/1/67, HDT). The same suggestion was made by another commentator. ${ }^{30}$ Hirschman refused to accept this recommendation.

In September 1966, a consultative committee summoned by the International Bank met to decide on the publication of Hirschman's report. Richard Demuth, who had associated with Hirschman in Colombia, was summoned to the meeting as representative of the Brookings Institution. Demuth justified his absence but submitted an opinion in which he deplored the absence of an operationally useful analysis of the merits and priority of the otter projects, or even of suggestions for improving these.

The criticisms of lack of operationality left Hirschman unmoved. Instead, he reproduced his objections to the techniques used by the International Bank in his preface to Development Projects. He did not apologize or seek to compromise. Symptomatically, he refers to the chapter in which he enunciates the principle of the hiding hand as "the most speculative chapter of the book, close to a provocation" (our emphasis). Having defined the tone, he directed his fire against the critics who accused his comments of lacking in operationality. He began in a conciliatory tone: nothing could be less operationally useful, he agreed, then stating that the underestimation of the costs and difficulties of the project was, from time to time, beneficial in the sense of releasing creative energies which otherwise would have gone unnoticed. This cautious introduction does not shift him, however, from his position. He then defended the thesis that hidden rationalities formed part of a hidden agenda, that of conferring a sense of mystery and surprise to the search for the same rationalities, which "has much in common with the highest quests of humanity".

\section{Academic bias}

Hirschman's report was also criticized for its style, specifically on the supposedly academic tone, in the negative sense of the expression, adopted by the author in narrating his visits. A specialist commented in a caustic tone that Hirschman was incapable of distinguishing a project report from an academic dissertation: “...the Doctor may have a point, but it must be remembered that our project reports are not academic dissertations”. ${ }^{31}$ On this occasion, the "point” to which the technician referred was Hirschman's criticism of the rule that defined that loans should be channeled through autonomous agencies.

30 11/4/67 AS to AOH. It is interesting to note that Hirschman thanked Stevenson in the preface to his book, something which he did not do with regard to the other technicians of the International Bank who made pronouncements on his report.

${ }^{31}$ 9/8/65, memo, ADS to BC (emphasis in the original). 
In an internal memorandum, another technician contrasted the academic with the decision maker. The author stated that the lack of an "exercise” such as the one developed by Hirschman was an attempt to reconcile very different approaches, when "a marriage is sought between two incompatible viewpoints, that of the decision maker and of the academic in search of the truth”. 32

In this respect, it is possible to agree that there is a difference in style between the two types of professionals, the academic, on the one hand, and the specialist of an institution such as the International Bank with practical concerns, on the other. The flaw in this criticism is nevertheless that it opposes the search for truth to the taking of a technical position, curiously suggesting that finding the truth should not be an objective of the decision maker.

\section{The change of course}

I have highlighted in this article Albert Hirschman's concern with the proper performance of his role as a money doctor and, as a result of this concern, his contribution to the systematization of evaluation procedures within an institution directed towards the promotion of development. But the lacuna that this article has sought to fill is more limited. My goal is to show how the divergence between Hirschman and the International Bank's technicians created the stimulus for a change in direction of the author's career.

It is opportune here to establish an analogy with migratory processes, since the episode suggests the simultaneous presence of factors of repulsion and attraction. On the one hand, the narrated incidents contributed decisively to the author's decision to abandon the field of economic science. In the new preface to Development Projects Hirschman confesses the "relief and satisfaction” that he experienced, "with more than the usual intensity", when he handled the manuscript to the Brookings Institution. At least in his "more exalted moments”, he looked at the book as the final volume of a unified trilogy.

On the other hand, the attention which Hirschman devoted to the social dimensions of the projects was a stimulus for him to pursue the broader field of social sciences, where a broader approach to economic development processes was needed and welcome. As pointed by various commentators (Bianchi 2007; Frobert and Ferraton 2003; Lepenies 2009; Meldolesi 1995; Schön 1994, among others), one of the recurrent features of Hirschman’s work is his tendency to jump over interdisciplinary barriers. This is no chance characteristic, and was already present in his previous works. After the completion of Development Projects, however, the movement was more far-reaching, representing a visible step outside the field of economics.

32 15/9/65, memo, DSB to BC. 
The criticisms of Hirschman by the International Bank's technicians were directed to one of the author's major intuitions, which would serve as a hook for a recurrent hypothesis in his later writings: that the future is indeterminate and that many important consequences of the implementation of projects are not foreseen. (Hirschman 1998, p. 96)

In the adventure of human existence, as he says, positive consequences may arise from favorable circumstances in which human creativity finds elements to bypass difficulties. This fascination with novelty and lack of confidence in forecasts is accentuated in the retrospective that he would later make of his career: "I simply think that I am not much interested in forecasts; they are not part of my theoretical impulses. ... My aim, in any event, is not to forecast tendencies; rather I am trying to understand what may possibly happen and to shift people’s focus in that direction.” (Hirschman 1998, p. 96)

This basic idea is the germ of Hirschman's conception of the process of social learning. For the author, risky decisions implying exposure to error generated learning opportunities. The implementation of a development project promoted a type of learning which emanates from practice, in which the trends deriving from previous decisions are corrected and mechanisms are built to overcome difficulties which were not and could not have been on the planner’s horizon. As Schön (1994, p.83) stresses, Hirschman saw the source of capacities necessary for solving problems, in the process of confronting them, hence in action itself. $^{33}$

The notion of unbalanced development, which finds one of its first and best qualified defenders in Hirschman, goes together with this recognition of the importance of learning from experience. An unbalanced development process is also a learning process, full of tensions, conflicts and difficulties. If well channeled, these forces may give life to dispersed energies. In learning by doing obstacles are transformed into spurs, and endorphins are released. (Schön 1994, p.71). ${ }^{34}$

The critics certainly have a point in their assessment of the report. In reality, they acted defensively, defending themselves from Hirschman's criticisms. Their negative reaction to the notion of unintentional

33 In the notebook in which he noted his observations from his visit to farmers in the Italian Mezzogiorno, Hirschman clearly expressed his interest in the process of learning of local authorities and farmers. According to him, they had confronted "the technical, social, economic and administrative problems that have arisen and the manner in which they have been resolved.” (AOH Papers, G. S. Mudd Library, Box 12). The author consulted a rich psychological literature on the topic of learning.

${ }^{34}$ On this point, there is an elegant annotation in Hirschman's field notebooks: "You have to do all these fool things before you do the sensible things”. Once again, he alludes to a learning process carried out on the basis of practice, which discards cake recipes and seeks solutions to problems as these are faced. 
consequences is not out of place. Indeed, while the occurence of unintentional consequences might be a reasonable claim, it is not reasonable to expect that such consequences will always be beneficial, as pointed out in below:

Applications of the "Hiding Hand" principle would mean, in effect, that developing countries and development assistance agencies should emphasize projects which promise to involve the greatest difficulties in order to build up the ability of the administrators in the developing country to analyse those difficulties and find solutions to them. Fortunately, while the argumentation is cleverly presented, few readers are likely to take it seriously. ${ }^{35}$

On this matter, Streeten (1984) suggests a symmetric inverse principle to the hiding hand, which he called the "principle of the hiding fist", where undesirable unforeseen consequences would occur. Any development agency must analyze in advance the chances of success of a given project, and if it is true that it is impossible to predict the future perfectly, the claim that the course of a project must be evaluated for its unforeseen consequences remains something reckless.

As said before, Hirschman does not deny the possibility of undesirable consequences, but he concentrates on episodes where the unexpected consequences are advantageous. Moreover, he rejects the use of current techniques of project evaluation, conversely, to make this task much more dependent on the intuition of the analyst, on the "flair" which he might have for locating the creative solutions that would overcome bottlenecks. As he states in the new preface to Development Projects:

Moreover, when I wrote this book in the middle sixties, the scientific determination of correct investment choices seemed to be within reach. [...] In the World Bank, investment choices and decisions were similarly expected to be made more rational through various devices known as 'shadow prices', 'social benefit-cost analysis,' and other sophisticated new techniques. In this intellectual atmosphere, it was to act as something of a spoilsport to call attention to very different, and much more problematic levels of concern about projects:...” (Hirschman 1994, p. viii)

Together with Schön (1994, p. 79), it is possible to ask wheter it is reasonable to suppose that all types and degrees of difficulty are salutary for development. Or only some of them, in well-defined circumstances? If the latter is the reply, how do we distinguish one from the other?

In defense of Hirschman's position, it is not possible to endorse the pretence of the International Bank's specialists of having found the perfect indicator, capable of reflecting all of the dimensions of a development project. On the one hand, because this presupposes a pinnacle of econometric sophistication, which is certainly difficult to achieve; on the other hand, because it is set forth as a justification for

\footnotetext{
${ }^{35}$ 9/13/1966, RHD to RNA.
} 
disregarding the social dimensions of projects. It is the same tired old story, if it's difficult to measure, then it should be moved out of the way...

The fact that Hirschman did not succeed in convincing his fellow workers of the need to consider the social dimensions may have been an important factor in the disillusion that he experienced with regard to economics and economists. This paper claims that this might have been responsible for his next move, the last straw that led him to take the decision of moving to neighboring territories.

Hirschman's next book, Exit, Voice and Loyalty, published in 1970, already lies on the other side of the fence which isolates economists from the other social scientists. In retrospect, this was a surprise with an advance warning.

\section{Final considerations}

In this article, I have described an important phase in the professional career of Albert Hirschman, surrounding the field research that he undertook in 1964-65 on 11 projects of the International Bank for Reconstruction and Development. The results of this research were set forth in the book Development Projects Observed, a text which represented the culmination of the author's pioneering work in the field of development economics and precedes a turning point in his writings.

I have sought here to show the impasses that the author had to overcome in order to realize his proposal to the International Bank and subsequently, to transform the report of his trip into a book. The disagreements are emblematic of the conflicts affecting a young institution, which took on the complex task of promoting economic development, at theoretical and operational level.

This certainly was not the only case when an author faced the resistance of his colleagues in the conclusions extracted from his field research and to his conception of the role of development agencies. May it serve as a counterpoint for new incursions of the same nature, with other authors, other scenarios and other institutions.

\section{REFERENCES}

Adelman, Jeremy (2008b). Pasajes: Albert Hirschman in Latin America. Retrieved July 15 2007, from Princeton University. Website: http://www.princeton.edu/ piirs/calendars/AdelmanPaperFinal.pdf Alacevich, Michele (2008). Visualizing uncertainties: Albert O. Hirschman and project evaluation at the World Bank. mimeo.

Bianchi, A. M. (2011). Visiting-economists through Hirschman's Eyes. European Journal of the History of Economic Thought, vol. 18, n.2, pp. 217-242.

Bianchi, A.M. (2007). Albert Hirschman na América Latina e sua trilogia sobre desenvolvimento econômico, Economia e Sociedade, 16 (2-30), p. 131-150. 
Flandreau, M. (2003). Introduction - money and doctors. In M. Flandreau (Ed.), Money Doctors - The Experience of International Financial Advising 1850-2000 (pp. 1-9). London: Routledge.

Frobert, L. \& Ferraton, C. (2003). L'Enquête Inachevée. Introduction à l'Economie Politique d'Albert O. Hirschman. Paris: Presses Universitaires de France.

Hirschman, A.O. (1958). The Strategy of Economic Development. New Haven: Yale University Press.

Hirschman, A.O. (1963/1968). Journeys Toward Progress. New York: Greenwood Press.

Hirschman, A.O. (1967). Development Projects Observed. Washington, D.C.: Brookings Institution.

Hirschman, A.O. (1981). Essays in Trespassing: Economics to Politics and Beyond. Cambridge University Press.

Hirschman, A.O. (1998). Crossing Boundaries - Selected Writings. Zone Books.

Krugman, Paul (1994). The fall and rise of development economics, in Rodwin e Schon In Rodwin, L. \& Schön, D.A. (Eds.). Rethinking the development experience - essays provoked by the work of Albert Hirschman. Washington, D.C.: The Brookings Institution.

Lepenies, P. H. (2009). Possibilismo: vida e obra de Albert O. Hirschman. Novos Estudos vol. 83, March, pp. 65-88.

Mason, E. S. e Asher, R.E. (1973). The World Bank since Breton Woods. Brookings Institution.

Meldolesi, L. (1995). Discovering the Possible: The Surprising World of Albert O. Hirschman. Notre Dame: University of Notre Dame Press.

Picciotto, Robert (1994). Visibility and Disappointment - The new role of Development evaluation. In Rodwin, L. \& Schön, D.A. (Eds.). Rethinking the development experience - essays provoked by the work of Albert Hirschman. Washington, D.C.: The Brookings Institution.

Schön, D.A. (1994). Hirschman's elusive theory of social learning. In Rodwin, L. \& Schön, D.A. (Eds.). Rethinking the development experience - essays provoked by the work of Albert Hirschman. Washington, D.C.: The Brookings Institution.

Streeten, Paul (1984). Comment. In: Meier, G. M. \& Seers, D. (eds.) (1984). Pioneers in Development. New York: World Bank and Oxford University Press, pp. 115-18. 